\title{
Estado da arte acerca da assistência de enfermagem na humanização do parto
}

\author{
Amélia Resende Leite ${ }^{a}$, Francisca Regicláudia Medeiros da Silva ${ }^{b}$ \\ aEnfermeira neonatal do Hospital Universitário Ana Bezerra (Ebserh), mestre em Saúde e Sociedade pela Universidade do Estado \\ do Rio Grande do Norte, Mossoró, RN, Brasil. \\ bEnfermeira, especialista em Neonatologia e em Obstetrícia pela Faculdade de Enfermagem Nova Esperança, Mossoró, RN, \\ Brasil..
}

RESUMO Foi realizada uma revisão integrativa com o objetivo de identificar a contribuição das pesquisas desenvolvidas sobre o estado da arte acerca da assistência de enfermagem na humanização do parto, em que as bases de dados BDENF e LILACS subsidiaram esta pesquisa. Para se aproximar da realidade, se optou por estudos publicados nos últimos 5 anos em formato de artigo, obtendo um total de 14 publicações que foram utilizadas nesta revisão. Os resultados mostraram a inserção da humanização no parto na formação da enfermagem e o incentivo fornecido pelo Ministério da Saúde, bem como o modelo hegemônico influenciando as condutas direcionadas aos partos. Conclui-se que é preciso que a enfermagem consiga apreender o seu real objeto e objetivo de trabalho e se conscientize do papel que tem no transcorrer de uma parturição satisfatória, em que a lembrança da paciente sobre esse momento atenda, e até supere, as expectativas criadas durante todo o período gestacional. Como também possa ocasionar aos profissionais envolvidos a satisfação e sensação do trabalho cumprido.

PALAVRAS-CHAVE cuidados de enfermagem; humanização; parto

Aceito 06 de fevereiro de 2020 Publicado online 20 de fevereiro de 2020

Cite este artigo: Leite AR, Silva FRM (2020) Estado da arte acerca da assistência de enfermagem na humanização do parto. Multidisciplinary Reviews 3: e2020008 DOI: $10.29327 /$ multi.2020008

\section{State of the art on nursing care in the humanization of childbirth}

ABSTRACT An integrative review aimed to identify the contribution of research conducted on the state of the art about the nursing care in the delivery of humanization in the databases BDENF and LILACS subsidized this research was conducted. To get closer to reality, it was decided by studies published in the last five years in article format, obtaining a total of 14 publications were used in this review. The results showed the insertion of humanization in childbirth in nursing education and encouragement provided by the Ministry of Health as well as the hegemonic model influencing behavior directed at birth. We conclude that it is necessary that nursing can grasp its real object and purpose of work and become aware of the role it has in the course of satisfactory parturition, where the memory of the patient about this time meets, and even exceeds, expectations created throughout pregnancy. As can also cause the professionals involved satisfaction and feel of the fulfilled work.

KEYWORDS: childbirth, nursing care, humanization

\section{Introdução}

De acordo com os relatos apresentados na literatura acerca da história dos partos, as mulheres grávidas eram assistidas na gravidez e no parto pelas parteiras e aparadeiras na comodidade de suas casas junto dos seus familiares. As parteiras eram pessoas respeitadas em toda a comunidade e estendiam seus cuidados para além do parto, fornecendo assistência e orientação com o recém-nascido e para o puerpério (Silvani 2010). 
Porém, a medicina ao tornar-se uma profissão alicerçada pela autoridade da linguagem técnica e da educação universitária, transformou-se em uma atividade reservada aos homens, de forma que a situação das parteiras e das curandeiras se tornou uma ameaça ao monopólio do saber. No final do século XVI, a profissão de parteira começou a sofrer um declínio, devido à utilização do fórceps obstétrico, que foi inventado pelo cirurgião inglês Peter Chamberlen, desafiando a noção do parto como um ato comandado pela vontade divina e introduzindo a noção do parto como um ato controlado pela vontade humana (Brasil 2010).

Lamentavelmente, a institucionalização do parto levou à medicalização e perda da autonomia da mulher como condutora do seu processo de parir. Dessa forma, o modelo de atenção ao parto e nascimento até hoje é marcado pela medicalização, pelo abuso de práticas invasivas e desnecessárias, potencialmente iatrogênicas, e pela prática abusiva da cesariana (Brasil 2001 apud Brasil 2010). Essa abordagem ao parto passou a ser um procedimento eletivo dificultando a adoção de condutas de humanização no processo natural de parto e nascimento (Martins et al 2012).

A humanização está relacionada a uma mudança na cultura hospitalar, com a organização de um cuidado realmente direcionado para as necessidades das mulheres e suas famílias; modificações na estrutura física, transformando o espaço hospitalar em um ambiente mais acolhedor e favorável à implantação de práticas humanizadas da assistência, ou seja, uma atuação profissional que respeite os aspectos da fisiologia do trabalho de parto/parto, a autonomia da mulher durante todo o processo e a escolha do seu acompanhante de preferência, que não intervenha desnecessariamente e que informe sobre todos os procedimentos que serão realizados (Dias e Domingues 2005 apud Souza et al 2013).

A desumanização do parto gera dentre outros eventos o isolamento da gestante de seus familiares, a falta de privacidade e o desrespeito à sua autonomia. Diante de tudo isso, o momento de parir fica marcado por rotinas rígidas que são adotadas sem a avaliação crítica caso a caso, ao mesmo tempo em que práticas adequadas para um bom acompanhamento do trabalho de parto não são realizadas, como o uso do partograma (Brasil 2001 apud Brasil 2010).

O parto realizado sem preceitos humanizados causa o esquecimento e abandono de algumas práticas que possibilitam que o nascimento do bebê tenha para a mulher e sua família um significado além do biológico. Ficando as instituições hospitalares com o controle do parto e do comportamento da parturiente (Dudou et al 2014).

A assistência ideal envolve a adequação dos recursos físicos, materiais e humanos, suficientes para transformar o ambiente em um espaço mais acolhedor e favorável à implementação das ações que são preconizadas pela política de humanização, entre as quais, permitir a presença do acompanhante e o envolvimento da família no processo de parturição, respeitar a privacidade da mulher, realizar procedimentos seguros e evitar práticas intervencionistas desnecessárias, favorecendo o transcurso natural do parto, além de orientar e informar a mulher visando a sua autonomia em relação às condutas e procedimentos (Bussanelle et al 2010).

A partir do aporte teórico, objetiva-se investigar o estado da arte acerca da assistência de enfermagem na humanização do parto. Desta forma, "bater na tecla" da humanização no parto é muito mais que se conscientizar e dispensar uma assistência respeitando o contexto da gestante. É possibilitar a realização de um sonho com um desfecho satisfatório, em que esta ao lembrar esse momento sinta-se feliz.

E que os profissionais envolvidos nesse momento sejam capazes prover assistência pilarizada nas políticas que regem e orientam condutas para esse momento e que compreendam a importância que têm para que isso de fato aconteça, garantindo a gestante o real protagonismo e a emoção que esse momento tem.

\section{Metodologia}

O percurso utilizado para a realização da revisão bibliográfica do tipo integrativa fundamentou-se nas publicações existentes na Biblioteca Virtual da Saúde, Bireme, em todos os índices, em que, primeiramente obteve resultado de 302 documentos.

As bases de dados BDENF e LILACS subsidiaram o estudo. A saber, foram utilizadas como descritores as palavras Enfermagem; Parto e Humanização. Foram empregados como critérios de inclusão os textos completos disponíveis, os que tinham como assunto principal: Enfermagem Obstétrica; Parto Humanizado; Enfermeiras Obstetras; Humanização da Assistência. Como critérios de inclusão: artigos Brasileiros, idioma em português, assunto da revista relacionado à 
enfermagem, e os que foram publicados nos últimos 5 anos em formato de artigo. Totalizou-se 14 publicações utilizadas nesta revisão.

\section{Resultados e discussão}

A tabela abaixo mostra as publicações utilizadas neste trabalho acerca do tema estado da arte acerca da assistência de enfermagem na humanização do parto.

Tabela 1 Publicações bibliográficas utilizadas nesta pesquisa.

\begin{tabular}{|c|c|c|c|c|}
\hline Autores & Titulo & $\begin{array}{l}\text { Ano de } \\
\text { publicação }\end{array}$ & Objetivo & Revista \\
\hline Costa e Schirme & $\begin{array}{l}\text { A atuação dos enfermeiros } \\
\text { egressos do curso de } \\
\text { especialização em } \\
\text { obstetrícia no nordeste do } \\
\text { Brasil: da proposta à } \\
\text { operacionalização. }\end{array}$ & 2012 & $\begin{array}{l}\text { Detalhar a atuação de } \\
\text { enfermeiros após especialização } \\
\text { em Obstetrícia na Região } \\
\text { Nordeste do Brasil e os } \\
\text { benefícios dessa atuação } \\
\text { consubstanciados em } \\
\text { premiações para a instituição em } \\
\text { que trabalhavam. }\end{array}$ & $\begin{array}{l}\text { Escola Anna Nery } \\
\text { Revista de } \\
\text { Enfermagem. }\end{array}$ \\
\hline Souza RM et al & $\begin{array}{l}\text { Parto natural domiciliar: } \\
\text { um poder da natureza } \\
\text { feminina e um desafio para } \\
\text { a enfermagem obstétrica }\end{array}$ & 2014 & $\begin{array}{l}\text { Identificar os motivos que } \\
\text { levaram as mulheres a optarem } \\
\text { pelo parto domiciliar; avaliar a } \\
\text { assistência obstétrica recebida } \\
\text { pelas parturientes em seus } \\
\text { domicílios. }\end{array}$ & $\begin{array}{l}\text { Revista Pesquisa } \\
\text { Cuidado é } \\
\text { Fundamental }\end{array}$ \\
\hline Versiani et al & $\begin{array}{l}\text { Significado de parto } \\
\text { humanizado para } \\
\text { gestantes. }\end{array}$ & 2015 & $\begin{array}{l}\text { Entender o significado de um } \\
\text { parto humanizado na concepção } \\
\text { de mulheres grávidas. }\end{array}$ & $\begin{array}{l}\text { Revista Pesquisa } \\
\text { Cuidado é } \\
\text { Fundamental }\end{array}$ \\
\hline Pimenta et al & $\begin{array}{l}\text { A cultura interferindo no } \\
\text { desejo sobre o tipo de } \\
\text { parto. }\end{array}$ & 2014 & $\begin{array}{l}\text { Compreender em que medida a } \\
\text { cultura influencia o processo de } \\
\text { mulheres no parto. }\end{array}$ & $\begin{array}{l}\text { Revista Pesquisa } \\
\text { Cuidado é } \\
\text { Fundamental }\end{array}$ \\
\hline Progianti et al & $\begin{array}{l}\text { A prática das enfermeiras } \\
\text { obstétricas nas } \\
\text { emergências vinculadas ao } \\
\text { Programa Cegonha Carioca. }\end{array}$ & 2014 & $\begin{array}{l}\text { Discutir a prática das } \\
\text { enfermeiras obstétricas nas } \\
\text { emergências das maternidades } \\
\text { vinculadas ao Programa } \\
\text { Cegonha Carioca. }\end{array}$ & $\begin{array}{l}\text { Revista } \\
\text { Enfermagem UERJ }\end{array}$ \\
\hline Souza et al & $\begin{array}{l}\text { Equipe de enfermagem e os } \\
\text { dispositivos de cuidado no } \\
\text { trabalho de parto: enfoque } \\
\text { na humanização. }\end{array}$ & 2013 & $\begin{array}{l}\text { Conhecer os dispositivos que } \\
\text { possibilitam a humanização do } \\
\text { cuidado no cotidiano da equipe } \\
\text { de enfermagem durante o } \\
\text { processo de parturição. }\end{array}$ & $\begin{array}{l}\text { Revista Pesquisa } \\
\text { Cuidado é } \\
\text { Fundamental }\end{array}$ \\
\hline Bruggemann et al & $\begin{array}{l}\text { A inserção do } \\
\text { acompanhante de parto } \\
\text { nos serviços públicos de } \\
\text { saúde de Santa Catarina, } \\
\text { Brasil. }\end{array}$ & 2013 & $\begin{array}{l}\text { Descrever a inserção do } \\
\text { acompanhante de escolha da } \\
\text { parturiente durante o trabalho } \\
\text { de parto, parto e pós-parto } \\
\text { imediato nos serviços vinculados } \\
\text { ao Sistema Único de Saúde que } \\
\text { prestam assistência ao parto em } \\
\text { Santa Catarina/Brasil, e } \\
\text { identificar os aspectos que } \\
\text { facilitaram e dificultaram esse } \\
\text { processo. }\end{array}$ & $\begin{array}{l}\text { Esc. Anna Nery } \\
\text { Revista } \\
\text { Enfermagem. }\end{array}$ \\
\hline Ferreira et al & $\begin{array}{l}\text { Expectativa das gestantes } \\
\text { em relação ao parto. }\end{array}$ & 2013 & $\begin{array}{l}\text { Descrever a expectativa das } \\
\text { gestantes em relação ao parto, } \\
\text { seus medos e anseios. As }\end{array}$ & $\begin{array}{l}\text { Revista Pesquisa } \\
\text { Cuidado é } \\
\text { Fundamental }\end{array}$ \\
\hline
\end{tabular}




\begin{tabular}{|c|c|c|c|c|}
\hline & & & $\begin{array}{l}\text { atividades que elas desenvolvem } \\
\text { para diminuir a ansiedade e a } \\
\text { participação da família. }\end{array}$ & \\
\hline Progianti e Hauck & $\begin{array}{l}\text { A implantação do modelo } \\
\text { humanizado de assistência } \\
\text { ao parto na cidade de Juiz } \\
\text { de Fora. }\end{array}$ & 2013 & $\begin{array}{l}\text { Analisar as estratégias de } \\
\text { implantação do modelo } \\
\text { humanizado de assistência ao } \\
\text { parto na cidade de Juiz de Fora, } \\
\text { no período } 1998 \text {-2001. }\end{array}$ & $\begin{array}{l}\text { Revista } \\
\text { Enfermagem UER }\end{array}$ \\
\hline Costa Júnior et al & $\begin{array}{l}\text { Condições institucionais } \\
\text { desfavoráveis à presença } \\
\text { do acompanhante: a visão } \\
\text { dos enfermeiros. }\end{array}$ & 2013 & $\begin{array}{l}\text { Compreender as dificuldades } \\
\text { encontradas por enfermeiros } \\
\text { que atuam em maternidades, } \\
\text { quanto à garantia da presença } \\
\text { do acompanhante durante o } \\
\text { parto. }\end{array}$ & $\begin{array}{l}\text { Revista Pesquisa } \\
\text { Cuidado é } \\
\text { Fundamental }\end{array}$ \\
\hline Silva et al & $\begin{array}{l}\text { A percepção de gestantes } \\
\text { de alto risco acerca do } \\
\text { processo de hospitalização }\end{array}$ & 2013 & $\begin{array}{l}\text { Compreender o processo de } \\
\text { hospitalização na ótica da } \\
\text { gestante de alto risco. }\end{array}$ & $\begin{array}{l}\text { Revista } \\
\text { Enfermagem UER }\end{array}$ \\
\hline Busanello et al & $\begin{array}{l}\text { Parto humanizado de } \\
\text { adolescentes: concepção } \\
\text { dos trabalhadores da } \\
\text { saúde. }\end{array}$ & 2011 & $\begin{array}{l}\text { Analisar diferenças e } \\
\text { semelhanças na concepção do } \\
\text { que seja uma assistência ideal às } \\
\text { adolescentes em um centro } \\
\text { obstétrico, de acordo com a } \\
\text { categoria funcional dos } \\
\text { trabalhadores de um hospital } \\
\text { universitário do Sul do Brasil. }\end{array}$ & $\begin{array}{l}\text { Revista } \\
\text { Enfermagem UER }\end{array}$ \\
\hline Figueiredo et al & $\begin{array}{l}\text { Ocorrência de episiotomia } \\
\text { em partos acompanhados } \\
\text { por enfermeiros obstetras } \\
\text { em ambiente hospitalar. }\end{array}$ & 2011 & $\begin{array}{l}\text { Analisar a ocorrência de } \\
\text { episiotomia e sua relação com a } \\
\text { paridade das mulheres assistidas } \\
\text { por enfermeiros obstetras de } \\
\text { uma maternidade pública do } \\
\text { município do Rio de Janeiro. }\end{array}$ & $\begin{array}{l}\text { Revista } \\
\text { Enfermagem UER }\end{array}$ \\
\hline Oliveira et al & $\begin{array}{l}\text { Percepção de puérperas } \\
\text { acerca do cuidado de } \\
\text { enfermagem durante o } \\
\text { trabalho de parto e parto. }\end{array}$ & 2011 & $\begin{array}{l}\text { Conhecer a percepção de } \\
\text { puérperas acerca do cuidado } \\
\text { oferecido pela enfermeira } \\
\text { durante o trabalho de parto e } \\
\text { parto. }\end{array}$ & $\begin{array}{l}\text { Revista } \\
\text { Enfermagem UER }\end{array}$ \\
\hline
\end{tabular}

As literaturas pesquisadas mostram que a equipe assistente ao parto é consciente sobre a assistência ideal ao parto que se coaduna com o ideário de atenção humanizada, no entanto reconhecem que alguns aspectos importantes ainda precisam ser incorporados (Busanelo et al 2011).

O parto humanizado é compreendido como aquele em que o profissional tenha como prerrogativa o relacionamento empático e a competência técnica que propicie à mulher a vivência de um trabalho de parto e parto fisiológico como protagonista durante este processo. Nesse mesmo trabalho foi verificado que as gestantes definiram que o parto humanizado deve ser pautado nas bases filosóficas da humanização do parto e nascimento, preconizado pelo Ministério da Saúde, que tem como princípios o relacionamento interpessoal e uma assistência competente (Versiani et al 2015).

Pode-se perceber por meio de relatos de Souza et al (2014) que a motivação para a escolha das gestantes de um parto fora do modelo institucionalizado está relacionada à multifatores como personalidade, estilo de vida, visão de mundo e experiências vivenciadas com seus ascendentes.

Constatou-se que a via de parto desejada pela maioria das entrevistadas durante todo o seu processo gestacional foi o parto normal, mas que a maioria não conseguiu realizar esse desejo, devido à influência e às intervenções recebidas do médico, retirando da mulher a sua autonomia no processo da parturição (Pimena et al 2014). 
Faz-se saber que a satisfação profissional se mostra como elemento importante para o desenvolvimento de um cuidado humanizado. Assim, a equipe de enfermagem tem papel importante no cuidado à mulher no processo de parturição, implementando dispositivos importantes na condução da integralidade da assistência (Souza et al 2013).

Estudos de Costa e Schirme (2012) relatam incentivos do Ministério da Saúde para a implantação de novos modelos assistenciais nos cursos de especialização em enfermagem obstétrica, incentivos esses que Ihe rendem premiações e encorajamento à humanização no parto.

Um alerta é feito nos estudos de Progianti et al (2014) sobre a metodologia da especialização em enfermagem obstétrica em que diz que a prática da enfermeira obstétrica, no módulo acolhimento, não deve ser realizada por uma práxis reiterativa e que, mesmo que seja pautada na humanização, não pode sofrer influência do modelo biomédico hegemônico. Esse alerta deve ser considerado, pois foi observado que o próprio ensino teórico reforça o modelo biomédico, tão distante de uma assistência humanizada e das reais necessidades das parturientes (Soares et al 2014).

Sugestões de por onde começar a humanização no parto são averiguadas por meio de Souza et al (2013) que diz que o acolhimento é o primeiro vínculo humanizador estabelecido com a mulher, por meio de orientações fornecidas, dentre outras condutas, que remeterão à mulher uma sensação de segurança que contribuirá favoravelmente para o processo de parturição.

O cuidado oferecido pela enfermagem foi percebido através de orientações, apoio emocional, contato direto (toque) e realização de procedimentos da rotina obstétrica, além da visibilidade da satisfação quanto à profissão, sendo imprescindível para proporcionar conforto e bem-estar, apesar de ainda não poder ser caracterizado como humanizado em sua totalidade (Oliveira et al 2011).

Sobre a presença dos acompanhantes dessa gestante no momento do parto, a maioria dos serviços os permite. No entanto, em alguns deles essa prática ainda é implementada com restrições, pois a escolha da parturiente não é respeitada e impede-se a permanência no momento do parto (Bruggemann et al 2013).

Progianti e Hauck (2013) apresentaram em suas pesquisas que a falta de apoio das instâncias administrativas quanto à implementação da lei, a estrutura física inadequada e a resistência por parte dos profissionais foram os pontos mais citados como empecilhos à ocorrência do parto acompanhado. No entanto, faz-se necessário buscar maneiras de transpor essas barreiras e garantir o direito conquistador (Costa júnior et al 2013).

Gestantes confessaram que o medo e ansiedade, malformação congênita, enxoval do bebê foram suas principais preocupações no período gestacional, e o que elas mais desejam era a participação do marido e da mãe. Assim, é cada vez mais necessárias ações de promoção da saúde e prevenção de complicações em gestantes, além de grupos e atendimento para esclarecimento de dúvidas e planejamento do parto e puerpério (Ferreira et al 2013).

Segundo Soares et al (2014) pedem que a equipe de enfermagem jamais priorize o tratamento medicamentoso e deixe de lado o cuidado humano, que não fique limitada ao procedimento, ou seja, não reproduza o modelo de assistência médica, cumprindo simplesmente a prescrição médica que, muitas vezes, não atende as necessidades da mulher.

\section{Considerações Finais}

A finalização desse estudo mostra que a humanização é um conceito conhecido, desde a formação, por todos os profissionais que compõe a equipe multiprofissional que assiste ao parto, em especial da equipe de enfermagem. No entanto, apesar das mudanças que vêm ocorrendo para que a humanização aconteça, a revisão bibliográfica permite afirmar que os partos se encontram arraigados na comodidade do mecanicismo do modelo biomédico que se detém prioritariamente à retirado do feto.

No entanto, é preciso que a enfermagem consiga apreender o seu real objeto e objetivo de trabalho e se conscientize do papel que tem no transcorrer de uma parturição satisfatória, em que a lembrança da paciente sobre esse momento atenda, e até supere, as expectativas criadas durante todo o período gestacional. Como também possa ocasionar aos profissionais envolvidos a satisfação e sensação do trabalho cumprido.

Colocar em prática todos os princípios norteadores do Ministério da Saúde, por meio de suas políticas de humanização no parto, é um desafio a ser vencido e isso certamente acontecerá um dia, pois é sabido que fazer a 
humanização no parto perpassa o querer. São necessárias condições ambientais, estruturais, humanas, dentre outras. Para tanto, é primordial que a pretensão de humanizar comece a partir do momento que a mulher adentra a Instituição hospitalar.

\section{Declaração de conflito de interesse}

Os autores declaram que não há conflitos de interesse.

\section{Referências}

Brasil (2010) Ministério da Saúde. Secretaria de Atenção à Saúde. Parto e Nascimento Domiciliar Assistidos por Parteiras Tradicionais. Brasília: Editora do Ministério da Saúde. Acesso em: out 06, 2019.

Bruggemann O, Oliveira ME, Martins HEL, Alves MC, Gayeski, ME (2013) A inserção do acompanhante de parto nos serviços públicos de saúde de Santa Catarina, Brasil. Escola Anna Nery Revista de Enfermagem 17:432-438.

Busanello J, Kerber NPC, Filho WDL, Lunardi VL, Mendonza-Sassi RA, Azambuja EP (2011) Parto humanizado de adolescentes: concepção dos trabalhadores da saúde. Revista enfermagem UERJ 19:218-223.

Costa AANM, Schirmer J (2012) A atuação dos enfermeiros egressos do curso de especialização em obstetrícia no nordeste do Brasil: da proposta à operacionalização. Escola Anna Nery 16:332-339.

Costa Júnior PB, Carvalho IS, Macedo JBPO (2013) Condições institucionais desfavoráveis à presença do acompanhante: a visão dos enfermeiros. Revista de pesquisa: cuidado é fundamental 5:671-680.

Dodou hd, Rodrigues DP, Guerreiro EM, Guedes MVC, Lago PN, Mesquita NS (2014) A contribuição do acompanhante para a humanização do parto e nascimento: percepções de puérperas. Escola Anna Nery 18:262-269

Ferreira la, Silva JAJ, Zuffi FB, Mauzalto ACM, Leite CP, Nunes JS (2013) Expectativa das gestantes em relação ao parto. Revista de pesquisa: cuidado é fundamental 10:450-457.

Figueiredo GS, Santos TTR, Reis CSC, Mouta RJO, Progianti JM, Vargens OMC (2011) Ocorrência de episiotomia em partos acompanhados por enfermeiros obstetras em ambiente hospitalar. Revista enfermagem UERJ 19:181-185.

Martins CA, Almeida NAM, De mattos DV (2012) Parto domiciliar planejado: assistido por Enfermeiro Obstetra. Enfermeria global 27:312-317.

Oliveira ASS, Rodrigues DP, Guedes MVC (2011) Percepção de puérperas acerca do cuidado de enfermagem durante o trabalho de parto e parto. Revista enfermagem UERJ 19:249-254.

Pimenta LF, Silva SC, Barreto CN, Ressel LB (2014) A cultura interferindo no desejo sobre o tipo de parto. Revista pesquisa: cuidado é fundamental 6:987-996.

Progianti JM, Hauck FT (2013) A implantação do modelo humanizado de assistência ao parto na cidade de Juiz de F ora. Revista enfermagem UERJ 21:324-329.

Progianti JM, Pereira ALF, Sé CCS (2014) A prática das enfermeiras obstétricas nas emergências vinculadas ao Programa Cegonha Carioca. Revista enfermagem UERJ 22:742-747.

Silva MRC, Vieira BDG, Alves VH, Rodrigues DP, Vargas GS, Sá AMP (2013) A percepção de gestantes de alto risco acerca do processo de hospitalização. Revista enfermagem UERJ 21:792-797.

Silvani, CMB (2010) Parto Humanizado: uma Revisão Bibliográfica. Universidade Federal do Rio Grande do Sul. Especialização em saúde pública, Faculdade de Medicina.

Souza CM, Ferreira CB, Barbosa NR, Marques JF (2013) Nursing Staff and the Care Devices in the Childbirth Process: Focus on Humanization. Journal of Reserarch fundamental care on line 5:743-754.

Souza RM, Soares LS, Quitete JB (2014) Parto natural domiciliar: um poder da natureza feminina e um desafio para a enfermagem obstétrica. Journal of Reserarch fundamental care on line 6:118-131.

Versiani CC, Barbieri M, Gabrielloni MC, Fustinoni SM (2015) The meaning of humanized childbirth for pregnant women. . Journal of Reserarch fundamental care on line 7:1927-1935. 